\title{
XVIII. Observations and experiments undertaken with a view to determine the quantity of sulphur contained in sulphuric acid; and of this latter contained in sulphates in general
}

\author{
Richard Chenevix Esq. F.R.S. M.R.I.A.
}

To cite this article: Richard Chenevix Esq. F.R.S. M.R.I.A. (1801) XVIII. Observations and experiments undertaken with a view to determine the quantity of sulphur contained in sulphuric acid; and of this latter contained in sulphates in general, Philosophical Magazine Series 1, 11:42, 112-118, DOI: 10.1080/14786440108675965

To link to this article: http://dx.doi.org/10.1080/14786440108675965

$$
\text { 曲 Published online: } 18 \text { May } 2009 .
$$

Submit your article to this journal $\square$

$$
\text { Џlll Article views: } 3
$$

Q View related articles ¿ 
fome importance. But whatever reafon there was to think, by arguing upon its chemical properties, that I had really fucceeded in improving its medicinal virtues, it ftill remained to be proved, by actual experiment, that the hoped-for fuccefs was not merely conjectural. To afcertain this, I gave fome of my powder to Dr. Crichton, Dr. Babington, and Mr. Abernethy; gentlemen whofe extenfive practice and acknowledged fkill fufficiently enabled them to judge of its medical properties. They all concur in opinion, that, in its general effects, it agrees with Dr. James's powder and the pulvis antimonialis; but that it is more mild, and confequently may be given in larger quantities, feldom producing naufea or vomiting in dofes of lefs than eight or ten grains.

XVIII. Obfervations and Experiments undertaken witb a Vierw to determine the Quantity of Sulphur contained in Sulphuric Acid; and of this latter contained in Sulphates in general. By Richard CHBNevix, Efq. F.R.S. M.R.I.A.*

I

N a paper which I had the honour to prefent to the Royal Society of London, and the fubject of which was the analyfis of fome arfeniates of copper and of iron, I had occafion, in examining many pyrites, matrices of thofe ores, to remark the very great inequality which prevailed in the refults of repeated experiments, made with a view to determine the proportion of fulphur. But I foon perceived that the inaccuracy was caufed by a partial combuftion and acidification of the radical, through the means of the nitric acid employed to diffolve the ore.

Having therefore, in the ufual manner, afcertained what quantity of that ingredient remained untouched, I was forced to feek the reft of it in the liquor which had wathed the various precipitates. To obtain it, I poured a folution of nitrate of barytes into thofe wafhings when all the other fubftances had been carefully feparated, and was thereby enabled to precipitate, in a ftate of purity, the fulphate of barytes, formed by that earth, and by the portion of fulphur originally acidified in the firtt treatment of the ore by nitric acid. To come at the knowledge of the proportion of fulphur contained in a given quantity of fulphate of barytes, I had recourfe, in the firft inftance, to the quantity of fulphur faid by Lavoifier to be contained in fulphuric acid; and, in the

* From the Tranfactions of the Rojal Lrifh Academy. 
next, to the proportions of the latter, announced in the fynoptic tables of Fourcroy, as entering into the compofition of fulphate of barytes. According to the former of thofe chemifts, 100 parts of fulphuric acid contain 71 of fulphur and 29 of oxygen; and again, in adopting the proportions of the latter, we have 33 per cent. of acid in fulphate of barytes. But if 100 contain 7 I of fulphur, 33 muft contain 23.43. Confequently, for every ros parts of fulphate of barytes, I was to allow 23.43 of fulphur. But, by the refults of my analyfes, I had fuch quantities of fulphate of barytes as induced me to doubt the accuracy of one or other of the ftatements by which I eftimated the quantity of real fulphur contained in the ore.

No perfon is better acquainted than our celebrated prefident with the many difficulties that occur in the analyfis of falts in general, particularly with regard to the quantity of real acid they may contain. It has been a work of trouble to the ableft chemifts, and they have not always agreed in their refults. The proportions announced by Fourcroy may therefore be doubted, in common with thofe of the other learned operators to whom I have alluded.

The real quantity of acid produced by the combuftion of any acidifiable bafis, can be determined by one or other of the following methods only : by direct combination in fome falt, the proportions of which are already known; or by obtaining, in a ftate perfectly free from water, the acid refulting from fuch combution. To the former method, the general objections againft all analyfes of falts muft apply. The latter is ftill more defective. It is by no means certain that we have ever yet obtained any acid in a ftate of perfect ficcity, mlefs we except the phofphoric and the arfenic; for even the cryftallized vegetable acids retain a portion of water in their cryftallization. It is not that I abfolutely deny our having obtained them fo; but I fay merely that we have no proof. It would indeed be fetting narrow bounds to the perfection of nature to affert, that no combuftible body could, when faturated with oxygen, affume of itfelf the ftate of liquidity; or that the oxide of the particular fubftance called bydrogen muft be prefent to confer that property. Doubtlefs fulphuric acid may, as well as water, contain in itfelf fo juft a proportion of fpecific heat, as to remain liquid at the temperature of our globe, and under the preffure of our atmofphere. But both water and fulphuric acid being eafily volatilized, and having a powerful affinity for each other, it is not eafy, if even poffible, by diftillation, to feparate them with fufficient accuracy in experiments of delicate inquiry. VOL. XI. 
A fecond fource of ertor, therefore, remained open in this branch of the calculation, which gave the proportion of 23.43 of fulphur, as that contained in 100 parts of fulphate of barytes.

However, before I would allow myfelf to call in queftion fuch authorities as thofe I have quoted, I inftituted the following experiments:-In a tubulated glafs retort I put 100 parts of purificd fulphur, and poured upon them ftrong nitric acid. A quilled receiver, plunging into a Woulfe's apparatus, was adapted to the retort; and all being well luted, I proceeded to difiti. The liquor which came over was poured back fevcral times upon the fulphur, until the whole was diffolved. The water which had come over, and that through which the nitrous gas, produced during the operation, had paffed, were effayed for fulphureous acid, and no traces of it could be found. No fulphur had been volatilized, therefore no fufpicion could remain that all was not converted into fulphuric acid. The liquors which were in the various parts of the apparatus were united, and to them was added a fufficient quantity of nitrate of barytes. The whole was craporated gently; becaufe, though I am well acquainted with the very little folubility of fulphate of barytes, I well know that nitric acid will retain a finall portion of it, particularly when formed in a liquor where that acid abounds. In a firft experiment I obtained $69+$ from 100 of fulphur; in a fecond, 348 from 50 ; and, in a third, 347 from the fame quantity. But the fimple rule of three reduced thefe quantities to 14.6 or 14.4 per cent. of fulphur contained in fulphate of barytes; a difference wholly to be neglected. If, therefore, we take 14.5 as the average for the quantity of fulphur contained in 100 parts of fulplsate of barytes, we thall not be far from the truth. From the accordance of thefe experiments, repeated and varied, I had now no doubt but concerming the fource where I was to leek the error, which gave 23.43 as the jufl proportion.

To afcertain this point, I operated in the following manner:-I prepared fome lime as pure, I believe, as chemical means can procure it. I digefted white marble in muriatic acid; and, by leaving an excefs of the earth, was certain that, by the fuperior affinity of line for that acid, nothing elfe had been taken up. Ifpon trying the folution with ammonia, no precipitate took place. By means of carbonate of potah, I feparatcl the lime in the ttate of carbonate; and, after well wafhing the precipitate, expofed it in a platina crucible to a violent heat till the weight no longer diminithed. I am acquainted with no more elficacious method 
to prepare lime fit for the delicate purpofes of fcientific chemiftry.

One hundred parts of this lime were diffolved in dilute muriatic acid, in the fame platina crucible, previoufly weighed; and then fulphuric acid was added in fufficient quantity. Sulphate of lime was precipitated; and the veffel was expofed to a heat, at firft gentle, to evaporate the liquor; and then, by degrees, raifed to a temperature which could expel every thing but the combined fulphuric acid, and leave the fulphate of lime completely calcined. The crucible with the falt was then weighed, and the autgmentation was 76 . It appears to me, that, if we admit (and I fee no reafon that we hould not adnit it) that calcince lime and calcined fulphate of lime are wholly exentpt from water, it muft be clear that the 76 additional weight were fulphurie acid; and that the fulphuric acid muft in this ftate, more than in any other, approach nearer to what may be termed abfolutely real acid. One hundred parts of calcined fulphate of lime contain, therefore,

$$
\begin{array}{ll}
\text { Lime } & -\quad 57 \\
\text { Sulphuric acid } & -\quad 43 \\
\hline 100
\end{array}
$$

By the former experiments (thofe made upon fulphur converted into acid, and then united to barytes,) we had the quantity of fulphur contained in fulphate of barytes. By the latter (thofe made by direaly combining lime with fulphuric acid) we had the proportion of real acid contained in calcined fulphate of lime. Confequently, by knowing the ratio that fulphate of barytes bears to fulphate of lime, with regard to the acid in each, we thall arrive at the knowledge of the quantity of fulphut contained in real fulphuric acid. For this purpofe, I attempted to diffolve, in water, 100 parts of fulphate of lime. But finding in this method of proceeding a confiderable inconvenience arifing from the great quantity of liquor neceffary to effect the folution of that falt, I had recourfe to the following expedient:-Upon 100 grains of calcined fulphate of lime, I poured fome oxalic acid, which attracts the bafis with an affinity fuperior to that exercifed by fulphuric acid. Oxalate of lime was here formed; but oxalate of lime is foluble in a very fmall excefs of any acid. A little muriatic acid operated a complete folution; and thus a great quantity of fulphate of lime required but little water to diffolve it. Into this liquor, muriate of barytes was poured, and fuffered to remain fome time, gently heated. By thefe means any oxalate of barytes that might have been formed, was retained in folution by the original 
excefs of acid; and the entire quantity of fulphate of barytes was depofited. Of the exactnefs of all thefe methods, which I ufed as the inftruments by which I afcertained thefe refults, I convinced myfelf by various preliminary experiments. After the ufual filtration, wathing and drying at the gentle heat of a fand-bath, I obtained in one experiment 185 , in another 183 , and, laftly, in another 180 . This difference does not exceed the limits of what all perfons converfant in analytic chemiftry will allow to experiments of this nature. We may therefore take 183 as the mean proportion; confequently we fhall fay, that 183 of fulphate of barytes contain the fame quantity of fulphuric acid as 100 of fulphate of lime; and $183: 43::$ 100:23.5. Therefore 23.5 is the proportion of acid in 100 of fulphate of barytes. But we have before feen that 14.5 of fulphur, acidified by nitric acid, form that portion of fulphuric acid contained in 100 of fulphate of barytes, viz. 23.5. We mult now fay, that $23.5: 14.5:: 1.00: 6$ I.5, and the fourth term will be the proportion of fulphur $=6 \mathbf{6 1 . 5}$, which combined with 38.5 of oxygen will form 100 of real fulphuric acid.

In neither of the proportions, whether it be of the acid contained in the falt, or of the combuttible bais contained in the acid, do I agree with the two chemifts whom I have quoied. This juftly excited fome doubts in my mind, and led me to repeat my experiments. Nor fhould I yet be thoroughly fatisfied, if I could not, upon other grounds than by fuppofing inaccuracy in them, account for the apparent differences. We mult ever exprct to fee the errors of our predeceffors corrected by men much inferior in abilities, but who, by poffefing more certain means, fupply the want of genius and invention. At the time in which the experiments were made that determined the proportion of 33 per cent. of fulphuric acid in fulphate of barytes, it was not known that we had never obtained any barytes pure; and that a confiderable portion of carbonic acid refitied the action of every degrce of heat that had been applied to carbonate of barytes. The fact was, I believe, firtt obferved by Pelletier, but the method of avoiding the inconvenience was pointed out by Vauqudin. He decompoles nitrate of barytes by fire, and a moderate deoree of heat is fufficient to expel all the acid and the water. The chemitis I bave mentioned performed fynthetic experiments by combining, directly or indirectly, fulphuric acid, and fuch barytes as they imagined to be pure. The conftant fimilarity of their refults is fufficient to prove the accuracy of their operations; but, working upon an impure fubttance, they mutt have been contented with a fimilarity of error. 
Three caufes may exift which are capable of accounting for any variation, whether in plas or in minus, that might have appeared in the experiments, by which Lavoifier determined the quantity of fulphuric acid obtained by the combuftion of fulphur in oxygen gas.

Ift, A part of the fulphur may be volatilized during combuftion.

$2 d$, All the fulphur may not be converted into fulphuric acid, but part may remain in the ftate of fulphureous acid.

3 d, In rectifying, fome acid may come over along with the water; or, vice verfit, fome water remain with the acid. Thefe confiderations will excufe me for having propofed a doubt, where the authority of fo great a man exifts againft the experiments which I have related.

The method which I had ufed to afcertain the quantity of fulphur in an ore had been practifed by Taffaert (Annales de Cbimie, No. 82: Analyfis of Cobalt from Tunaberg); but he calculated according to the proportions of Lavoifier and of Fourcroy. In another paper by Thenard, (Annales de Cbimie, No. 96,) he ftates the proportions of fulphuric acid, obtained by treating fulphur with nitric acid, to be

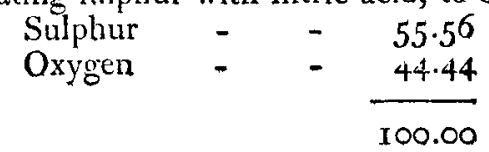

but in the extract given by Guyton in that number of the Annales de Cbimie, the mode of operation is not defcribed. Calcined fulphate of barytes is eftimated in the fame paper to contain

$$
\begin{array}{ll}
\text { Barytcs - } & -74.82 \\
\text { Sulphuric acid } & -\quad 25.18 \\
\hline 100.00
\end{array}
$$

which proportions are as near to what $I$ had found as can be expected; for fulphate of barytes does not contain more than 3 per cent. of water of cryftallization, and they muft be deducted from the quintal.

Having determined with accuracy the proportion of acid in any infoluble fulphate, it is eafy to proceed to the determination of that contained in any other fulphate. The docimaftic art, or analytic chemiftry, in general, cannot however expect to derive fuch advantages from the knowledge of foluble falts, as of thofe which, from their infolubility, may be ufed with accuracy, in delicate experiments, to determine the proportions of the conflituent parts of badies. H 3 
But if with this mode of operating we compare the quantities of real acid, faid (in thofe excellent tables with which Mr. Kirwan has enriched the fcience) to be contained in fulphuric acid of different fpecific gravities, each will ferve as a proof of the validity of the other; and perhaps demonftrate, that fulphuric acid, without the intervention of water, may enjoy liquidity at the temperature and preffure which act upon our globe.

XIX. Experiments on Platina. By L. PRoust.

[Continued from p. 55.]

\section{Of the Cryffallization of Solutions of Platina.} 7

$\mathrm{HE}$ fmall yellow, red, and fand like grains which are depofited at the bottom of the united folutions, and which fometimes affume the octaedral form, are generally taken for muriate of platina. The quantity of thefe cryftals, which is always very fmall, does not increafe by concentration; which, however, ought to be the cafe, if thefe cryftals were really muriate of platina. No more of them appear in folutions from which they have been once feparated; and their feparation is even complete a long time before the moment when the real muriate of platina begins to cryftallize.

Thefe cryftals are a double falt, compofed of muriate of platina and potanh, as will be feen hereafter: they are formed from the fmall quantity of potafb which, by the inadvertency of the workmen, remains in the neck of the retorts, when preparing nitric acid, and from that alfo which is carried over in the diftillation itfelf; for nitre is always found, after the rectification of aquafortis, at the bottom of the retorts. 'The greater part of thofe who have operated on platina having in general cmployed the acids fold in the fhops, we need not be furprifed that they hould have found cryftalline depofits of the kind here alluded to, and that none of them are ever feen in folutions made on purpofe with acids well purified.

If fome of thefe cryftals be heated in a glafs tube clofed at one end, their nature may be foon diftinguifhed; becaufe the muriatic acid, charged with the oxygen of the metal, is volatilized in gas; while the platina, reduced to the metallic ftate, and mixed with the muriate of potah, remains at the bottom of the tube.

Lewis, in my opinion, is the only perfon who has accurately obferved the cryftallization of platina. The folution 